\title{
Quantitative proteomic analysis of cell envelope preparations under iron starvation stress in Aeromonas hydrophila
}

\author{
Zujie Yao ${ }^{1,2}$, Zhihong Wang ${ }^{1,2}$, Lina Sun ${ }^{1,2}$, Wanxin Li ${ }^{1,2}$, Yan Shi ${ }^{1,2}$, Ling Lin ${ }^{1,2}$, Wenxiong Lin ${ }^{1,2,3^{*}}$ \\ and Xiangmin $\operatorname{Lin}^{1,2,3^{*}}$
}

\begin{abstract}
Background: Iron homeostasis is an essential process over the entire lives of both hosts and bacterial pathogens, and also plays roles in many other metabolic functions. Currently, knowledge is limited on the iron scavenging mechanism of the cell envelope in the aquatic pathogen, Aeromonas hydrophila. To understand the iron homeostasis mechanism in A. hydrophila, a dimethyl labelling based quantitative proteomics method was used to compare the differential expression of cell envelope proteins under iron starvation.

Results: A total of 542 cell envelope proteins were identified by LC-MS/MS, with 66 down-regulated and 104 up-regulated proteins. Bioinformatics analysis showed that outer membrane siderophores, heme and iron receptors, periplasmic iron binding proteins, inner membrane $A B C$ transporters and $\mathrm{H}^{+}$-ATP synthase subunits increased in abundance while iron-cluster proteins, electron transport chain and redox proteins were down-regulated. Further q-PCR validation, in vivo addition of exogenous metabolites, and an enzyme inhibition assay revealed that redox, the energy generation process, and ATP synthase elevated the susceptibility of A. hydrophila to iron starvation.
\end{abstract}

Conclusions: Our study demonstrates that the redox and energy generation process, and ATP synthase in A. hydrophila may play critical roles in iron acquisition under conditions of iron-stress. An understanding of the iron scavenging mechanism may be helpful for the development of strategies for preventing and treating A. hydrophila infection.

Keywords: Aeromonas hydrophila, Cell envelope, Dimethyl labeling, Iron homeostasis

\section{Background}

Iron is the second most abundant metal in the earth's crust; however, ferrous iron, the useable form, is scarce, due to an oxidative environment [1-3]. It is an essential element for most bacteria with irreplaceable functions in many basic biological processes, including the $\mathrm{Fe}^{3+}$ cofactor of metabolic respiratory chain reactions. These include photosynthesis, $\mathrm{N}_{2}$ fixation, methanogenesis, respiration, tricarboxylic acid (TCA) cycle, and DNA biosynthesis $[2,4]$. To prevent the invasion of bacteria, hosts, including humans, have evolved to minimize the concentration of free iron by secreting transferrin and lactoferrin, which have high affinity for iron [5].

\footnotetext{
* Correspondence: Iwx@fjau.edu.cn; xiangmin@fafu.edu.cn

${ }^{1}$ Fujian Provincial Key Laboratory of Agroecological Processing and Safety

Monitoring, School of Life Sciences, Fujian Agriculture and Forestry

University, Fuzhou 350002, People's Republic of China

Full list of author information is available at the end of the article
}

Therefore, bacteria have evolved effective ways to survive in this harsh environment. Under this process, cell envelope proteins in Gram-negative bacteria, including periplasmic, outer and inner membrane proteins, are essential in the transport of iron related compounds into the intracellular environment. The cell envelope proteins related to iron homeostasis mechanisms are well studied in Escherichia coli, in which outer membrane proteins (OMPs), such as CirA, FecA, FepA, BtuB, FhuA, FhuE, and YbiL, serve as receptors of siderophores or heme to transport iron into the periplasmic space [6]. Some other OMPs, such as OmpW, TsX and OmpX function as either iron exporters or receivers [7]. During this process, the periplasmic protein TonB and inner membrane proteins (IMPs) ExbB and ExbD form a protein complex to mediate the transport of iron compounds from the 
outer membrane to periplasm [8]. The periplasmic binding proteins, such as FepB, FhuB, FhuD and $\mathrm{FecB}$ in Escherichia coli deliver iron compounds to ATP-binding cassette $(\mathrm{ABC})$ transporters in the cytosolic membrane and then into the cytosol $[5,6,9,10]$. Meanwhile, iron starvation triggers some complex networks and metabolic pathways via the fur gene family which regulates iron homeostasis [11].

It is well known that the aquatic pathogen, Aeromonas hydrophila, causes serious disease outbreaks in numerous farmed fish populations, and leads to big economic losses in the aquaculture and fishery industry, annually [12-14]. However, knowledge is limited on the iron scavenging mechanism of this pathogen, especially for the role of the cell envelope proteins during the competition for iron resources with the host. In this study, the differential expressions of the envelop proteins of $A$. hydrophila were compared in the presence/absence of the iron chelating medium by a dimethyl labelling based quantitative proteomic method. Bioinformatics analysis found some important biological processes involved. Furthermore, some of the altered proteins were validated by quantitative polymerase chain reaction (q-PCR) analysis and subjected to related functional validation. We provide the first report, to our knowledge, on the iron homeostasis functions of cell envelope proteins in A. hydrophila.

\section{Results}

\section{Characterization and identification of the envelope} protein fraction in A. hydrophila

According to the growth curve of $A$. hydrophila, the

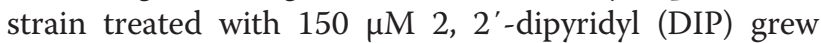
slower than the control strain, especially after the middle exponential phase (Fig. 1a). To investigate the biological functions of envelope proteins in iron homeostasis, bacterial envelope proteins in presence/absence of DIP with the concentration of $150 \mu \mathrm{M}$ were extracted. SDS-PAGE separation showed some significant differences between DIP treatment and the control, and the whole cell lysates of $A$. hydrophila were made to probe the cell envelope preparation enrichment in the preparations (Fig. 1b). After comparing with these differences between DIP treatment and non-treatment, the extracted cell envelope proteins of $A$. hydrophila were then in-solution digested and labeled by Stable Isotope Dimethyl. Further LC MS/MS analysis identified 837 proteins with at least two peptides required for identification and a false discovery rate (FDR) less than $1 \%$ filtered in the total number of 1024 proteins (Table 1 and a complete list in Additional file 1: Table S1).

According to the online location prediction software, we found that these identified proteins included 447 cytoplasmic proteins (account for $43 \%$ ), 323 inner membrane proteins (31 \%), 138 periplasmic proteins
(13\%), 71 outer membrane proteins (7\%), 55 extracellular proteins (5\%), and 12 fimbrium proteins (1\%) with some overlapping proteins in the predicted locations (Fig. 1c).

\section{Differential expression of envelope proteins in $A$. hydrophila in iron-limited medium}

To further investigate the biological behavior of $A$. hydrophila under iron-limiting conditions, dimethyl labeling based quantitative proteomic technology was used to analyze the differential expression of envelope proteins. In the 837 identified proteins, 170 membrane envelope proteins were found to be differentially expressed. Taking overlapping locations into account, 104 proteins including 37 OMPs, 50 IMPs, 25 periplasmic proteins and three fimbrial proteins were up-regulated, while 66 proteins including seven OMPs, 39 IMPs and 28 periplasmic proteins decreased in abundance in the iron starvation medium.

Of these altered proteins, seven outer membrane proteins, A0KJP9, R4W0J5, R4VC61, A0KJN3, A0KGW8, R4VA05, and K1JLD4, which serve as ferrienterobactin, ferrichrome, hemin, siderophore and heme receptors, and at less five periplasmic $\mathrm{ABC}$ transporters (R4VG84, R4VTC6, R4VQ44, A0KG07, and R4VTR3) and ExbB family protein (R4W2T6) increased in abundance. However, OmpW (R4VIJ9) of A. hydrophila presented a down-regulated trend, although its biological function is still unknown. Interestingly, besides the outer membrane siderophore receptors, there were more outer membrane proteins altered, including R4VAF7 (OmpK family, up), A0KK67 (FadL family, up), A0KLX3 (outer membrane translocase, down), R4VCH3 (OmpD family, up), R4VRX0 (major outer membrane lipoprotein, up), A0KNY2 (ABC-type efflux system secretin component, up), R4VNF2 (OmpA family lipoprotein, up), A0KHF6 (Maltoporin, down) and R4VR45 (Chitoporin, up).

Meanwhile, seven c-type cytochromes (A0KQV7, R4VNL8, R4VQS4, R4V7Y6, R4VH33, A0KL28, and R4VF53) decreased in abundance. These proteins contained iron ion binding domains suggesting they reduce the use of iron and lead to the decrease of the respiratory electron transfer chain under iron starvation. On the contrary, ATP synthase subunits (R4VLV7, R4W2U5, and R4VJ80), the final terminal point of cellular respiration, were found to be up-regulated. While the purpose of this opposite phenomenon is unknown, we hypothesize that it provides an ATP source for ferrous iron scavenging.

Proteomics analysis also showed that almost all of the altered proteins located in the extracellular space were up-regulated, such as hemolysin (R4VSQ0 and D2XPP9) and fimbrial protein (R4VSB4) could be explained as an attempt by the cell to strengthen the acquisition of scarce iron ions from outside and try to escape from the 
a

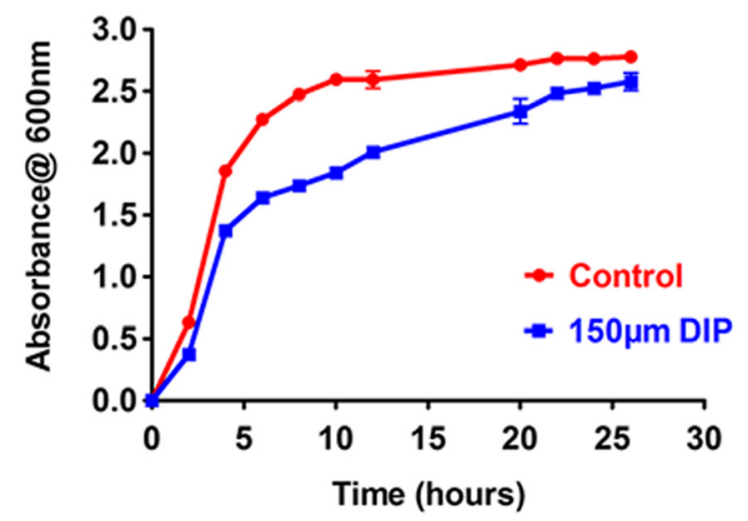

C

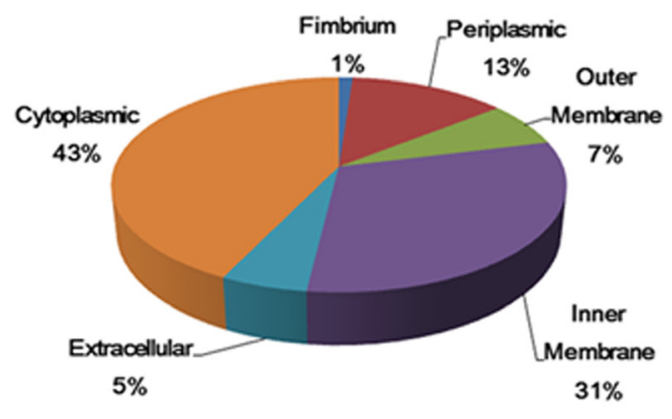

e

Biological Process

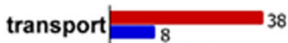

macromolecule metabolic process $\begin{array}{r}\text { transport } \\ =10\end{array}$

organonitrogen compound metabolic process

organic substance biosynthetic process $\square 7_{7}^{0}$

cellular biosynthetic process

small molecule metabolic process -10

cellular nitrogen compound metabolic process $\square$

oxidation-reduction process $\nabla_{8}{ }_{15}$

organic substance catabolic process ${ }_{6}$

cellular catabolic process 6

generation of precursor metabolites and energy

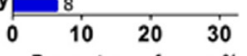

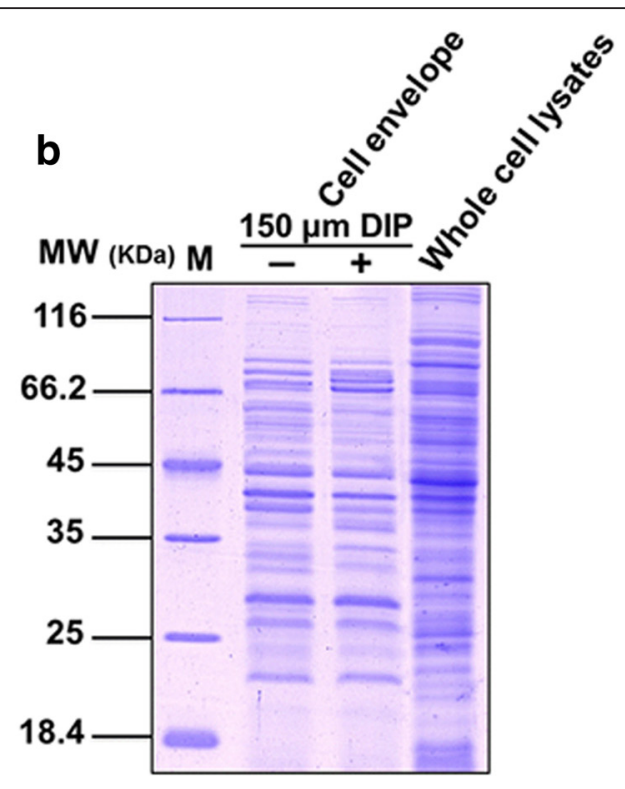

d

Species distribution

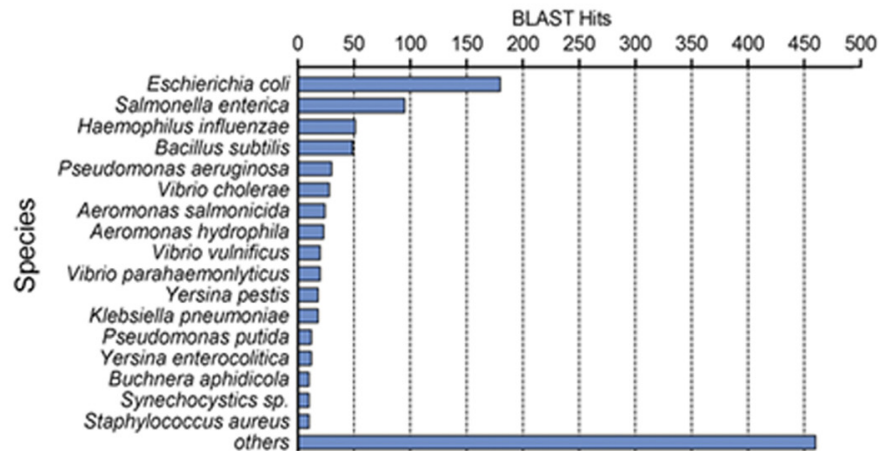

f

Molecular Function

substrate-specific transmembrane transporter activity 12 cation binding 12 peptidase activity 11

nucleoside phosphate binding 8 hydrolase activity 6 active transmembrane transporter activity $6 \quad 6$ Down serine hydrolase activity $6 \quad$ Up passive transmembrane transporter activity 5 nucleoside binding 5

iron chelate transmembrane transporter activity 5 anion binding 5 carbon-oxygen lyase activity $\square_{4}$ iron-sulfur cluster binding $\square$ tetrapyrrole binding

Fig. 1 (See legend on next page.) 
(See figure on previous page.)

Fig. 1 Comparative characteristics of cell envelope protein of A. hydrophila in iron limited medium a Growth curve of A. hydrophila ATCC 7966 with and without $150 \mu \mathrm{M}$ DIP in LB medium; b CBB-stained SDS PAGE map of the cell envelope of A. hydrophila with and without $150 \mu \mathrm{M}$ DIP and whole cell lysates of $A$. hydrophila as the comparison. Lane M contained molecular mass standards; c The subcellular localization of the identified proteins from MS results predicted by online software Gneg-mPLoc; d Blastp top-hit species distribution using local Blast2GO. Numbers of top hit sequences from Blastp were calculated for each species; $\mathbf{e}$ and $\mathbf{f}$ Gene ontology categories for the differentially expressed proteins of $A$. hydrophila in iron starvation using local Blast2GO analysis and classified into biological processes (e) and molecular functions (f). The red and blue bars indicate up-regulation (red) and down-regulation (b/ue) differential ratios of genes, respectively. Each related gene numbers are showed on the right of bars

threatening surroundings. In addition, many proteases such as Q49KA8 (Serine protease), A0KIU6 (Proprotein convertase P-domain), A0KGX4 (Putative metalloprotease), R4VU01 (Hg (II) reductase) and A0KFK2 (glycosidase) were found to increase in extracellular space.

\section{Investigation of the classification and functional annotation analysis of altered proteins}

To further characterize the altered envelope proteins, a biological functional classification was clustered using bioinformatic analysis. The local Blast2GO software was chosen to maximize homologous gene/protein annotations because of the limitation of Gene Ontology (GO) annotations of $A$. hydrophila. The BLASTP program was run against the Swiss-Prot database, producing 131 (74.0 \%) matches from a total of 170 candidates with blast expected values $\leq 10^{-3}$ using BLAST2GO. Figure $1 \mathrm{~d}$ shows the Basic local alignment search tool (BLAST) hit distribution across various species of organisms for all altered sequences in the dataset. Further analysis identified the most enriched GO terms comparing the up- and down-regulated proteins clusters including transport (22\% Go terms up-regulated and $6.3 \%$ downregulated), macromolecule metabolic process (11\% up, $7.8 \%$ down), oxidation reduction process (4.6\% up, $11.7 \%$ down), small molecule metabolic process (5.8\% up, $8.6 \%$ down), generation of precursor metabolites and energy (6.3\% down) in biological process category and cation binding (13\% up, $29.5 \%$ down), tetrapyrrole binding (13\% down), iron-sulfur cluster binding (8.2\% down), active transmembrane transporter activity $(6.5 \%$ up) and iron chelating transmembrane

Table 1 Selected identification of significantly differentially expressed proteins of A. hydrophila ATCC 7966 under iron stress using dimethyl labeling quantitative proteomics

\begin{tabular}{|c|c|c|c|c|c|c|}
\hline Accession Name & Description & Match peptides & Coverage \% & MW & Ratio & Location Prediction \\
\hline K1JDT3_AERHY & Uncharacterized protein TonB-dependent & 13 & 56.4 & 33.65 & 45.53 & PM. \\
\hline K1JLD4_AERHY & hemoglobin/transferrin/lactoferrin receptor family protein & 21 & 33.4 & 77.04 & 40.78 & OM. \\
\hline R4VT74_AERHY & Proprotein convertase P-domain-containing protein & 24 & 35.4 & 88.48 & 28.78 & Ex. \\
\hline AOKJP9_AERHH & TonB-dependent siderophore receptor & 39 & 61.8 & 71.66 & 23.97 & OM. \\
\hline R4VC61_AERHY & Hemin receptor & 30 & 52.8 & 80.03 & 22.83 & OM. \\
\hline R4VMU5_AERHY & Uncharacterized protein & 13 & 44 & 49.37 & 22.67 & Ex. \\
\hline D2XPP9_AERHY & Hemolysin & 30 & 53.3 & 68.78 & 22.46 & Ex. \\
\hline R4W1J6_AERHY & Methyl-accepting chemotaxis protein & 2 & 2.4 & 72.99 & 22.26 & IM. \\
\hline R4VA05_AERHY & Outer-membrane heme receptor & 39 & 66.9 & 76.73 & 19.06 & OM. \\
\hline A0KIU6_AERHH & Proprotein convertase P-domain & 21 & 31.8 & 88.41 & 15.73 & Ex. \\
\hline R4WH5_AERHY & Uncharacterized protein & 6 & 76.1 & 8.64 & 0.16 & IM. \\
\hline A0KL15_AERHH & Bordetella uptake gene family protein & 12 & 44.9 & 34.03 & 0.16 & IM. \\
\hline R4W91_AERHY & EcoEl R domain-containing protein & 2 & 2.7 & 85.41 & 0.15 & $\mathrm{IM}$ \\
\hline R4V7Y6_AERHY & Cytochrome c4 & 9 & 37.6 & 21.29 & 0.15 & PM. \\
\hline R4VH33_AERHY & Cytochrome c551 peroxidase & 9 & 28 & 35.62 & 0.15 & PM. \\
\hline A0KLX1_AERHH & DeCa-heme c-type cytochrome & 15 & 24.5 & 79.84 & 0.14 & CM. Ex. PM. \\
\hline R4VKJ3_AERHY & Uncharacterized protein & 2 & 14.6 & 17.35 & 0.13 & $\mathrm{IM}$ \\
\hline AOKL28_AERHH & Cytochrome c-type protein & 3 & 13.7 & 22.14 & 0.11 & PM. \\
\hline K1J5J8_AERHY & Uncharacterized protein & 19 & 26.9 & 72.17 & 0.11 & OM. \\
\hline R4VF53_AERHY & Cytochrome c553 & 10 & 66 & 15.31 & 0.09 & PM. \\
\hline
\end{tabular}

Note: PM., OM., IM., Ex. and CM. mean the location of periplasm, outer membrane, inner membrane, extracell and cytoplasm, respectively 
transporter activity (5.4 \% up) in molecular function category (Fig. 1e and f).

\section{Validation of selected altered proteins at the mRNA level using q-PCR}

According to the proteomic results and data analysis, up-regulated transport processes, down-regulated redox and energy generation process were the major response characteristics of envelope proteins in iron starvation. To confirm this, we investigated the mRNA levels of a total of 21 selected genes found to be altered in the proteomic analysis, using a q-PCR method. Of these 21 genes, five genes (R4VLV7, R4VV29, R4W2U5, R4VJ80, A0KQX7) were $\mathrm{H}^{+}$-ATPase subunits, seven genes (A0KNY2, A0KHF6, R4VG84, A0KJN3, R4W0J5, R4VCH3, A0KJP9) were related with the transport process, six genes (R4V7Y6, R4VF53, A0KL28, A0KQV7, R4VNL8, R4VH33) were involved in the redox process and three genes (R4VNP5, R4VS58 and K1JGN0) were involved in the energy generation process. Results showed that most of the transcription levels of these 21 related genes were consistent with our proteomics conclusions (Fig. 2). In the selected transport-process related genes, the mRNA level of A0KJP9, a TonBdependent siderophore receptor, displayed a very significant up-regulation (21.91 folds) under iron starvation, suggesting its crucial role in iron uptake. On the other side, the transcription of other candidate genes increased from 1.5 to 8.8 fold, except for R4VLV7 and R4VJ80, which only increased slightly, with a ratio of 1.2 and 1.3, respectively.

In the redox process and energy generation process, the down-regulated mRNA levels of R4V7Y6, R4VNP5, R4VF53, A0KL28, and R4VS58 were in agreement with protein levels, while K1JGN0, A0KQV7 only changed slightly. Interestingly, the transcription of R4VNL8 (ammonia-forming cytochrome c nitrite reductase) and R4VH33 (cytochrome c551 peroxidase) increased, contradictory to the proteomic results. In summary, up to $81 \%(17 / 21)$ of genes displayed the same directional change in both protein and mRNA levels, $19 \%(4 / 21)$ showed no correlation, while only $10 \%(2 / 21)$ were dysregulated in the opposite direction.

\section{TCA related exogenous metabolites elevate susceptibility} of $A$. hydrophila to iron starvation

In this study, we found the down-regulation of the TCA related energy generation processes under iron starvation, using a proteomics approach. We assume that the downregulation of the energy generation process takes part in the iron homeostasis mechanism rather than simply stimulation from iron depletion. To validate this, serial dilutions of the TCA related exogenous metabolites were added in LB medium with or without DIP to stimulate the TCA process. As shown in Fig. 3, low of concentration exogenous metabolites alone did not affect bacterial growth while high levels of metabolites, such as Oxaloacetic acid (OAA), $\alpha$-Ketoglutarate $(\alpha-K A)$, Succinic acid (SA) and Citric acid (CA), did depress the bacterial growth rate. However, when the exogenous metabolites were added in LB medium with $300 \mu \mathrm{M}$ DIP, most of them elevated susceptibility of $A$. hydrophila to iron starvation, especially $\alpha-K A$ and $C A$, which both depressed bacterial growth significantly at $8 \mathrm{mM}$ (Fig. $3 \mathrm{~b}$ and d).

\section{$\mathrm{H}^{+}$-ATP synthase activity was increased in the iron starvation environment}

We further confirmed the behavior of $\mathrm{H}^{+}$-ATP synthase under iron limited conditions. $\mathrm{H}^{+}$-ATPase activity was measured with a serial dilution of DIP treatment.

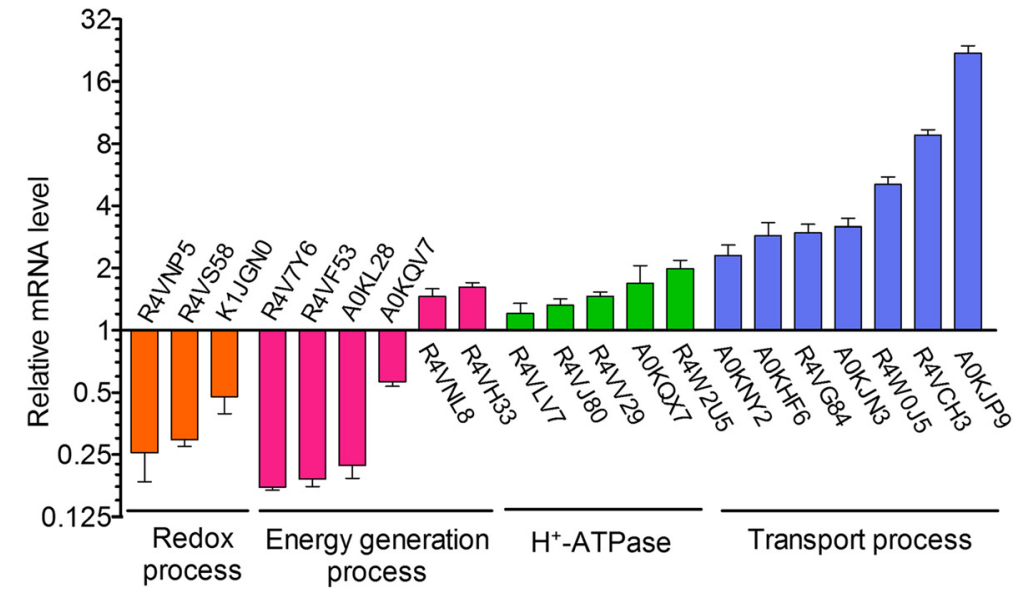

Fig. 2 The validation of relative expression behaviors of transport, redox, and energy generation processes were selected and verified by q-PCR The mRNA level of 12 transport related genes which were up-regulated at the protein level (blue), 6 oxidation-reduction and 3 energy generation process related genes which were down-regulated at the protein level (red), were analyzed by q-PCR 


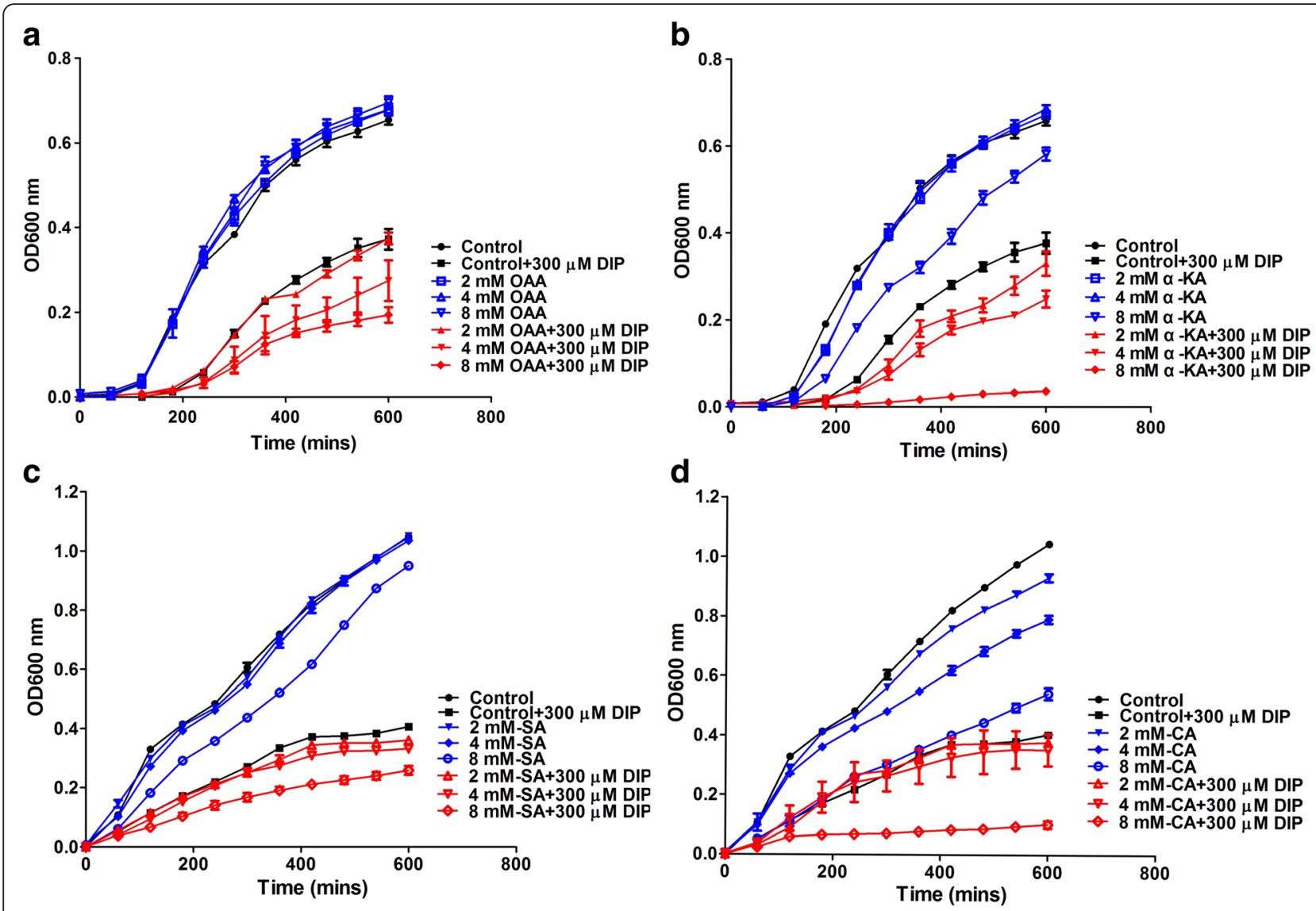

Fig. 3 Effect of exogenous metabolites on susceptibility of A. hydrophila to iron starvation. a-d The growth curve of A. hydrophila strain in $300 \mu M$ DIP $\mathrm{mM}$ oxaloacetic acid (OAA), a-ketoglutarate ( $(\mathrm{-}-\mathrm{KA})$, succinic acid (SA) and citric acid (CA) treatment, respectively. The concentration of these four reagents are in the gradient of $0,2,4$ and $8 \mathrm{mM}$. The growth kinetics of treated cells were recorded by absorbance measurements at OD600 $\mathrm{nm}$, at $30^{\circ} \mathrm{C}$ with the Multi-mode detection platform

Compared to control, the $\mathrm{H}^{+}$-ATPase activities of $A$. hydrophila were increased in response to iron starvation (Fig. 4a), which are consistent with our proteomics results. We then investigated the biological characteristics of $\mathrm{H}^{+}$-ATP synthase in iron starvation using N, N'-Dicyclohexylcarbodiimide (DCCD), an inhibitor of ATP synthase. When treated with $20 \mu \mathrm{g} /$ $\mathrm{mL}$ DCCD, the bacterial survival rate was significantly decreased by $7.5,117.2$ and 14.9 fold with the increase of DIP concentrations $150 \mu \mathrm{M}, 200 \mu \mathrm{M}$ and $300 \mu \mathrm{M}$, respectively (Fig. 4b). To further investigate the extent of functional differences under ironlimitation, an orthogonal test was performed by using serials of DIP and DCCD concentrations and then displayed as color grading according to their survival colony accounting (Fig. 4c). Results showed that, with the increasing of DIP plus DCCD treatments, the survival rates of $A$. hydrophila, were dramatically decreased.

\section{Discussion}

Aquatic pathogenic bacteria $A$. hydrophila cause a fulminant epidemic in aquaculture, including some extremely severe bacterial diseases, such as hemolytic ascitic disease, bacterial septicemia, and fulminant hemorrhage $[15,16]$. So far, the response mechanism of $A$. hydrophila under some metal ion deficient conditions is not clear. Other bacteria, in order to respond to physiological iron-deficient conditions, have evolved a series of strategies to compete with the host for the uptake of life-essential iron [17-19]. During this process, the cell envelope has an important effect on the extracellular and intrinsic communications due to its specific position, especially for the competition of essential nutrients in harsh environments [20,21].

In order to systematically study the iron acquisition mechanism of the bacterial cell envelope system under the external pressure of iron limiting conditions, a dimethyl labeling based quantitative proteomic strategy was used to compare the differential expression of cell 


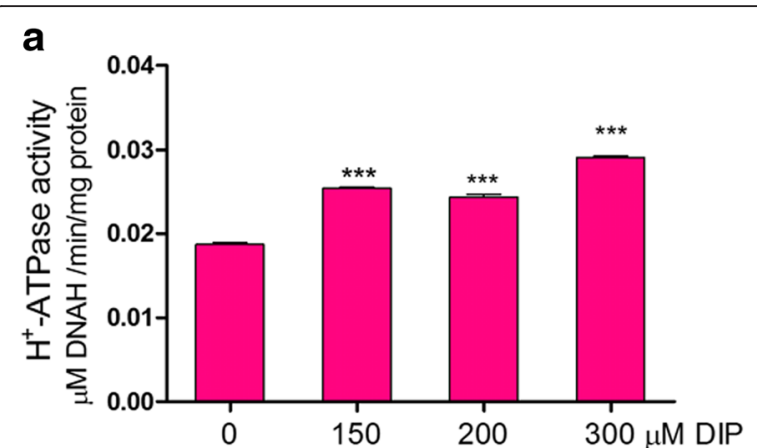

b

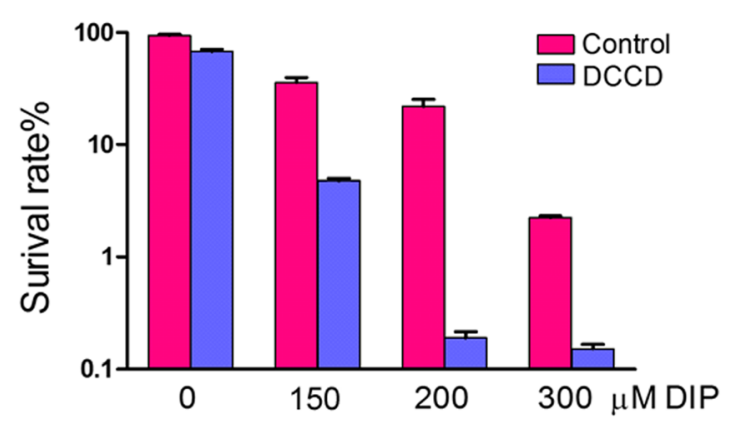

C

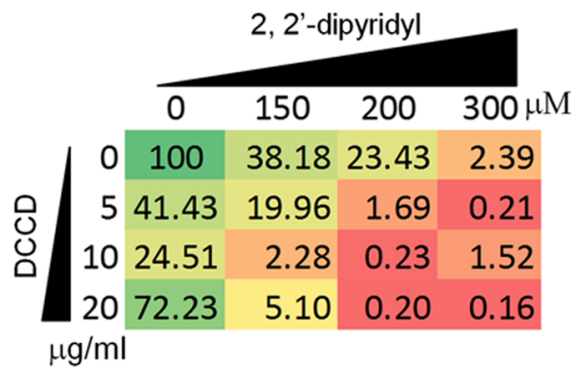

Fig. 4 The functional validation of ATP synthase under iron starvation conditions. a The $\mathrm{H}^{+}$-ATP synthase activity of $A$. hydrophila in a serial of DIP concentrations in 0, 150, 200 and $300 \mu \mathrm{M}$ were measured spectrophotometrically at $340 \mathrm{~nm}$ using the $\mathrm{H}^{+}$-ATPase assay kit b The survival ratio of $A$. hydrophila when treated with $20 \mu \mathrm{g} / \mathrm{mL}$ DCCD in a serial dilution of DIP concentrations in 0, 150, 200 and $300 \mu \mathrm{M}$ for $12 \mathrm{~h}$ and observed by colony counting, respectively. $\mathrm{c}$ Color grading of the effect of a serial of concentrations of DIP from $0 \mu \mathrm{M}$ to $300 \mu \mathrm{M}$ and DCCD from $0 \mu \mathrm{g} / \mathrm{mL}$ to $40 \mu \mathrm{g} / \mathrm{mL}$. The colony amounts of bacteria without treatment were normalized to 100 as control

envelope proteins in A. hydrophila. About $57 \%$ of cell envelope proteins were extracted and identified in the current study. Based on the fact that cytoplasmic proteins contributed to the major contamination in all reported extraction methods, the TSE (Buffer ingredients contain $0.2 \mathrm{M}$ Tris $-\mathrm{HCl}, \mathrm{pH}=8.0,0.5 \mathrm{M}$ sucrose, $1 \mathrm{mM} \mathrm{Na} \mathrm{N}_{2}$ EDTA) extraction used in this study was documented to produce the cleanest extraction of envelope proteins up to date [22]. Compared to the $52 \%$ enrichment ratio in $E$. coli, using the same method in the mentioned reference, the $57 \%$ of cell envelope proteins enriched in A. hydrophila, should be acceptable [21]. Thus, in this study we acquired an acceptable cell envelope protein enrichment in $A$. hydrophila.

In the present study, according to the final quantitative proteomic analysis, which can be summarized into the following statements: Firstly, the expression of iron source receptors, which are located in the bacterial outer membrane, induced iron scavenging. These are highaffinity iron chelators and competitively bind iron from iron sources. Actually, under iron deprivation, there are many reports about the upregulation of proteins involved in regular channel forming proteins, such as siderophore receptor channels, CirA, FecA, FepA, FhuA, FhuE, and YbiL in E coli [3], and other channel proteins, such as OmpX in E.coli [7]. Those results demonstrated the competitive uptake system of iron in A.hydrophila under iron-limiting conditions.

Secondly, after the ferri-siderophores and other iron sources specifically bind to outer membrane receptors, an energy generation system for transport is required. Because there was no ATP energy supply in the outer membrane, the ExbB-ExbD-TonB system assisted ferrisiderophores translocation from the outer membrane to the periplasm in A. hydrophila as well as in other bacteria [23-27]. Generally, it is provided the energy by the energy-transduction TonB-ExbB-ExbD protein complex, such like in E.coli [28]. Although we could not identify TonB and ExbD proteins in the current study, an ExbB family protein, R4W2T6 was up-regulated three fold, suggesting that TonB-ExbB-ExbD might participate in iron protein uptake in $A$. hydrophila as well. Besides, periplasmic iron binding proteins, such as the heme- and vitamin B12- binding proteins, and the associated cytoplasmic membrane ABC permease transporters mediated the transport of ferrisiderophore complexes across the periplasm and cytoplasm similar to the other fish pathogenic bacteria Edwardsiella ictaluri [29].

Thirdly, besides the siderophore receptors are located in outer membrane, there were many OMPs differentially expressed under iron starvation. In our previous study, we found that the outer membrane protein R4VIJ9 (OmpW) was down-regulated in E.coli in iron-limited medium [7]. Some other channel proteins were in the identical tread of down-regulated, such as and A0KLX3 (MtrB/PioB family decaheme), and also many found up-regulated channel proteins, such as R4VRK9 (sucrose porin), A0KMI4 (porin), R4VNF2 (OmpA family protein), Q4ZHS9 (major outer membrane protein) and A0KNY2 (outer membrane efflux protein) in iron starvation in this study as well. The biological functions related to iron depletion are largely unknown for these proteins. According to the fact that most of these proteins are the channels on outer 
membrane and control the influx or efflux of small molecular substrates, they might have an important effect on the controlling and monitoring of the cellular free iron concentration [30, 31]. Because of the channel characteristics of OMPs, the down-regulation of OMPs might influence the influx of iron related substrates, whereas the up-regulation of OMPs might affect the efflux function [32, 33]. Additionally, the peptidoglycanassociated lipoprotein, Pal, and periplasmic TolB increased under iron starvation. The Tol-Pal system was energized by the proton motive force and contributed to maintain the cell envelope integrity [34]. Since TolPal system related proteins are homologous with the TonB-ExbB-ExbD system, they may participate in the iron uptake for bacteria survival [35].

Fourthly, bacteria have to reduce their intracellular redox reaction rates because many functional related enzymes are iron-cluster proteins. Thus, the energy generation system and electron respiration chain were depressed under iron starvation. We assume that the down-regulation of the energy generation process takes part in the iron homeostasis mechanism rather than simply stimulation from iron depletion. The down-regulation of TCA cycle and its related proteins under iron starvation was reported in other bacteria species, such as FrdA, FrdB, FrdC and FrdC in E. coli [3], SdhA, CitG, CitB, CitC and PckA in Staphylococcus aureus [36]. Smaldone et al., proposed the derepression of Fur-regulated FsrA may repress expression of glutamate synthase (GltAB), and finally down-regulate TCA cycle intermediate $\alpha$-ketoglutarate, and DctP which imports succinate and fumarate [37]. Thus, the downregulation of TCA cycle under iron-deficient condition demonstrated that the stimulation of the TCA process depresses bacterial growth in iron starvation environment and plays an important role in iron homeostasis.

Finally, the reduction of the electron respiration chain, to some extent, might relieve the danger of bacterial reactive oxygen species (ROS) and help for survival [2, 38, 39]. On the other hand, cells require iron resources such as siderophores or heme urgently for iron homeostasis by transporting iron compounds from the periplasm to cytosol and this process consumes ATP [40, 41]. During this process, ATPase should be activated for ATP support. In this study, the down-regulation of the TCA cycle, cellular respiration and the increasing of ATPase were identified by proteomics and validated in mRNA level by q-PCR. This outcome was consistent with our proteomics result confirms the previous report that mRNA and protein levels do not correlate perfectly and suggests that protein post-translational modifications [42]. The intrinsic reason of this phenomenon remains largely unknown. To our understanding, ATPase subunits do not have iron-sulfur clusters and would not affect the use of limited iron resource [43]. The increasing expression of ATPase may be a compensation mechanism to produce ATP resource for ABC transport as much as possible in the environment where the proton motive force (PMF) is resulting in a decrease. To confirm this hypothesis, we investigated the ATP synthase function under iron limiting conditions using an enzyme activity assay and ATP synthase inhibitor. Our results validated that the activity of $\mathrm{H}^{+}$-ATP synthase was activated in iron starvation and the inhibition of its activity would increase the susceptibility of $A$. hydrophila to iron starvation. According to the proteomic results of cell envelope proteins involved in iron starvation, the scheme of iron uptake systems in $A$. hydrophila is represented graphically in the Additional file 2: Figure S1.

\section{Conclusions}

The aim of this study was to investigate the iron homeostasis mechanism in the aquatic pathogen, A. hydrophila. To our knowledge, this is the first report on the iron homeostasis functions of cell envelope proteins in A. hydrophila by using a dimethyl labeling based quantitative proteomic method. The transmembrane transporter activity and ATP synthase increased significantly in abundance to enhance iron transport and maintain cellular iron homeostasis, while redox processes, precursor metabolites, energy generation processes and other iron-sulfur cluster binding processes decreased significantly in abundance to alleviate the pressure of the iron-limitation, by reducing iron use. In general, this mechanism plays a crucial role in the signal transmission and regulation of the pathogenic bacteria under metal ion limited conditions. A deep understanding of the iron acquisition mechanism of bacteria in the metal ion deficient conditions provided a theoretical support for the invasion mechanism of $A$. hydrophila disease.

\section{Methods \\ Cultivation of bacterial strains}

In this study, A. hydrophila (ATCC7966) was kindly provided by Prof. Jijuan Cao from Liaoning Entry-Exit Inspection and Quarantine Bureau, Dalian, PR. China. This strain was grown in Luria-Bertani (LB) medium at $30{ }^{\circ} \mathrm{C}$. Iron limitation was conducted by the inclusion of a divalent metal chelator, the ferrous iron binding agent 2 , 2'-dipyridyl (DIP) (Sinopharm Chemical Reagent Co., Ltd, Shanghai, China) $[44,45]$, at 0 or $150 \mu \mathrm{M}$ in LB medium, respectively. The overnight culture was diluted 1:100 into fresh LB medium with $150 \mu \mathrm{M}$ DIP at $30{ }^{\circ} \mathrm{C}$ with shaking at $200 \mathrm{rpm}$ to late exponential phase (OD600 1.0).

\section{Cell envelope extraction}

The proteins from the $A$. hydrophila cell envelopes were extracted according to a modified osmotic shock method [22]. Briefly, cells were harvested at late exponential 
phase by centrifugation at $3,000 \times \mathrm{g}$ for $20 \mathrm{~min}$ at $4{ }^{\circ} \mathrm{C}$. TSE buffer (0.2 M Tris- $\mathrm{HCl}, \mathrm{pH}=8.0,0.5 \mathrm{M}$ sucrose, $1 \mathrm{mM} \mathrm{Na}{ }_{2}$ EDTA) was subsequently added to the pellet to extract cell envelope proteins by causing the cells to shrink and release their contents. After incubating on ice for $20 \mathrm{~min}$ and additional $20 \mathrm{~min}$ in the same volume of ice-cold water, the soluble envelope proteins were separated by centrifugation at $16,000 \times \mathrm{g}$ for $30 \mathrm{~min}$ at $4{ }^{\circ} \mathrm{C}$. Supernatants were concentrated with Amicon ${ }^{\oplus}$ Ultra-4 centrifugal filter devices with $3 \mathrm{~K}$ Da cut offs (Millipore), and then frozen at $-80{ }^{\circ} \mathrm{C}$ before use.

In-solution digestion and stable isotope dimethyl labeling The total cell envelope protein concentration was determined using a Bradford assay. Proteins from each sample $(100 \mu \mathrm{g})$ were reduced with a solution of $200 \mathrm{mM}$ Tris (2-carboxyethyl) phosphine (TCEP) at room temperature for one hour, and alkylated with $25 \mathrm{mM}$ Iodoacetamide (IAA) at room temperature in the dark for $45 \mathrm{~min}$ as described previously [46]. Treated samples were precipitated by adding six volumes of ice-cold acetone and incubated at $-20{ }^{\circ} \mathrm{C}$ for at least $12 \mathrm{~h}$. Then, the samples were centrifuged at $8,000 \times \mathrm{g}$ for $10 \mathrm{~min}$ at $4{ }^{\circ} \mathrm{C}$, and $100 \mu \mathrm{L} 200 \mathrm{mM}$ Triethylammonium bicarbonate (TEAB) was added for dissolution [47]. Finally, each sample was digested with $5 \mu \mathrm{g}$ Trypsin protease (Thermo Scientific) at a $1: 20$ ratio and incubated at $37{ }^{\circ} \mathrm{C}$ for $12-16 \mathrm{~h}$. About $25 \mu \mathrm{g}$ digested peptide from each group was taken out for further stable isotope dimethyl labeling, as described previously [48]. The labeling scheme was: $A$. hydrophila in LB medium with and without $150 \mu \mathrm{M}$ DIP as the heavy and light isotopes, respectively.

\section{LC MS/MS analysis for Q-Exactive}

Digested and labeled peptides were analyzed with a Q-Exactive mass spectrometer coupled to an Easy-nLC 1000 HPLC instrument (Thermo Fisher Scientific, Bremen, Germany). The peptide mixture was loaded onto an Easy-spray column (C18, $2 \mu \mathrm{m}, 100 \AA$, $75 \mu \mathrm{m} \times 50 \mathrm{~cm})$ and separated with a linear gradient of 3-90\% buffer $B$ $(0.1 \%$ Formic acid in acetonitrile) at a flow rate of $250 \mathrm{~nL} / \mathrm{min}$ over $180 \mathrm{~min}$. Normalized high-energy collision dissociation (HCD) was performed, with the collision energy set at $30 \%$. The instrument was operated in positive ion mode with an ion spray voltage of $2.3 \mathrm{kV}$, using a data-dependent top 20 method dynamically choosing the most abundant precursor ions. Isolation of parent precursors was performed with a $300-1800 \mathrm{~m} / \mathrm{z}$ range and MS/MS was acquired starting at $100 \mathrm{~m} / \mathrm{z}[49,50]$.

Fragmentation data were interpreted by Proteome Discoverer version 1.4 against the Aeromonas hydrophila database (download from Uniprot database on Dec.1st. 2014) with the search parameters including alkylated cysteine residue by iodoacetamide, trypsin digestion. Protein quantitation and confidence of the dimethyl labeling quantitative method were performed and evaluated using a highly conservative threshold (folds change $\geq 2.0$ or $\leq 0.5, \mathrm{FDR}<1 \%$ ). The identified proteins with at least two peptides matched and normalized with related peptides in the control were considered for further analysis. Each experiment was performed in at least triplicates and identified in three technical replicate experiments.

\section{Bioinformatics analysis}

The Gene Ontology (GO) terms of the differential proteins in this study were analyzed to characterize the related biological functions. To overcome the disadvantage of poor GO annotations in the A. hydrophila database, Blast2GO version 2.7.2 (http://www.blast2go.com/) was used, which is a homology-based approach for gene ontology enrichment analysis [51]. The protein subcellular locations were identified by the program Gneg-mPL oc version 2.0 (http://www.csbio.sjtu.edu.cn/bioinf/Gne g-multi/\#) which combines the gene ontology information and functional domain with the sequential evolution information for Gram-negative bacterial proteins [52].

\section{Validation of proteomic analysis}

To determine the mRNA expression, total RNA was isolated from cultured bacterial cells using a TaKaRa MiniBEST Universal RNA Extraction Kit (Takara Shuzo, Otsu, Japan) according to the manufacturer's instructions. Isolated RNA samples were eluted in $30 \mu \mathrm{L}$ RNase-free water and the cDNA was generated from $1 \mu \mathrm{g}$ total RNA using a PrimeScript ${ }^{\mathrm{m}} \mathrm{RT}$ reagent Kit with gDNA Eraser (Takara Shuzo, Otsu, Japan) after calculations to perform one round of the reverse-transcription reaction. The expression of Glyceraldehyde-3-phosphate dehydrogenase $(G A P-1)$ was detected as the internal endogenous control, and all samples were normalized to GAP-1 according to a previously described method (Table 2) [53].

All of the quantitative Real-time PCR reactions were carried out using SYBR ${ }^{\oplus}$ Premix Ex Taq ${ }^{\mathrm{TM}}$ II (Tli RNaseH Plus) (Takara Shuzo, Otsu, Japan). The conditions used for q-PCR were $5 \mathrm{~s}$ at $95^{\circ} \mathrm{C}, 34 \mathrm{~s}$ at $60{ }^{\circ} \mathrm{C}$, and then $40 \mathrm{cy}$ cles of $30 \mathrm{~s}$ at $95{ }^{\circ} \mathrm{C}$ and melt curve added. Gene expression values were determined by the $\Delta \Delta \mathrm{Ct}$ method, which was normalized to the level of GAP-1 measured in each sample and expressed relative to the value obtained in the indicated control sample [54]. All reactions were performed in a CFX96 Touch $^{\mathrm{Tm}}$ Deep Well Real-Time PCR Detection System (Bio-Rad). All primer sequences were designed using the software Primer Premier5. All experiments were performed at least in triplicate, independently. 
Table 2 Sequences of the primer pairs used in this study for q-PCR

\begin{tabular}{|c|c|c|c|c|c|c|}
\hline Name & Description & Primer & Sequence $\left(5^{\prime} \rightarrow 3^{\prime}\right)$ & $\begin{array}{l}\text { Nucleotide } \\
\text { position }\end{array}$ & $\begin{array}{l}\text { Product } \\
\text { size (bp) }\end{array}$ & Reference \\
\hline \multirow[t]{2}{*}{ AOKNY2 } & Outer membrane efflux protein & $\mathrm{F}$ & AGTTCGGTCAAGATGCTGTGG & 193 & 193 & This study \\
\hline & & $\mathrm{R}$ & CGATCTCCTGCTTGGTCTGC & 385 & & This study \\
\hline \multirow[t]{2}{*}{ AOKQX7 } & ATP synthase epsilon chain & $\mathrm{F}$ & CTCCGTTGCTGACTGCCATC & 116 & 166 & This study \\
\hline & & $\mathrm{R}$ & GCTITCGCCTCATCCAAATCG & 281 & & This study \\
\hline \multirow[t]{2}{*}{ R4VLV7 } & ATP synthase gamma chain & $\mathrm{F}$ & AGGCTTACGACAACGGTGAG & 473 & 199 & This study \\
\hline & & $\mathrm{R}$ & TAGCGAATCAGCAGGGTATCC & 671 & & This study \\
\hline \multirow[t]{2}{*}{ R4W29 } & ATP synthase subunit alpha & $\mathrm{F}$ & CAACGCCGAGTATGTAGAGAAG & 912 & 164 & This study \\
\hline & & $\mathrm{R}$ & GCTGTGAGGTCAGGAAGATC & 1,075 & & This study \\
\hline \multirow[t]{2}{*}{ R4W2U5 } & ATP synthase subunit b & $\mathrm{F}$ & ATTGCTGACGGTCTCTCTTCC & 55 & 150 & This study \\
\hline & & $\mathrm{R}$ & CTCATCAATGATCTGGGCTITACG & 204 & & This study \\
\hline \multirow[t]{2}{*}{ AOKJN3 } & Ferrichrome-iron receptor & $\mathrm{F}$ & GCTTCGGTCTTCCACATCAC & 1,606 & 176 & This study \\
\hline & & $\mathrm{R}$ & ATCTCCATATCCTGACGGGTATAG & 1,781 & & This study \\
\hline \multirow[t]{2}{*}{ R4W0J5 } & Ferrichrome receptor & $\mathrm{F}$ & GGCAAGAACGAGAAGCAGTATG & 1,216 & 150 & This study \\
\hline & & $\mathrm{R}$ & CTTGTAGGATTGGCTGGTGTTG & 1,365 & & This study \\
\hline \multirow[t]{2}{*}{ AOKHF6 } & Maltoporin & $\mathrm{F}$ & CCTTCGCCGTTGATTTCCAC & 125 & 165 & This study \\
\hline & & $\mathrm{R}$ & TCTTGCCGTCCTTGTTGAATAC & 289 & & This study \\
\hline \multirow[t]{2}{*}{$\mathrm{R} 4 \mathrm{VCH} 3$} & Outer membrane porin protein & $\mathrm{F}$ & TACAACCAGAACGACACCAAAC & 73 & 165 & This study \\
\hline & & $\mathrm{R}$ & GTATTCAGCGAAGCCGAACG & 237 & & This study \\
\hline \multirow[t]{2}{*}{ R4VG84 } & Peptide $A B C$ transporter periplasmic peptide-binding protein & $\mathrm{F}$ & GACAACAAGACGGTGCTGAC & 52 & 165 & This study \\
\hline & & $\mathrm{R}$ & CAGACGATAGACGGGTTTGC & 216 & & This study \\
\hline \multirow[t]{2}{*}{ R4VJ80 } & ATP synthase subunit beta & $\mathrm{F}$ & GGGTCTGGTGCTGGAAGTTC & 117 & 123 & This study \\
\hline & & $\mathrm{R}$ & ACCTGGATGGATTTACCGCTATTC & 239 & & This study \\
\hline \multirow[t]{2}{*}{ R4V7Y6 } & Cytochrome c4 & $\mathrm{F}$ & TCTGAACAGGACATGGAAGACC & 268 & 198 & This study \\
\hline & & $\mathrm{R}$ & GGACAGGCTCGGATACTTGG & 465 & & This study \\
\hline \multirow[t]{2}{*}{ R4VH33 } & Cytochrome c551 peroxidase & $\mathrm{F}$ & ACTCCAGCCTCAACTTCGTG & 269 & 181 & This study \\
\hline & & $\mathrm{R}$ & AAGTCCGCCTTGCCATACAC & 449 & & This study \\
\hline \multirow[t]{2}{*}{ AOKJP9 } & TonB-dependent siderophore receptor & $\mathrm{F}$ & AGACCGATCTGATGGATGACTC & 944 & 168 & This study \\
\hline & & $\mathrm{R}$ & CATTGGTGATGCTGCGACTG & 1,111 & & This study \\
\hline \multirow[t]{2}{*}{ AOKL28 } & Cytochrome c-type protein NrfB & $\mathrm{F}$ & GATGCCGCCTGTACCGACTG & 160 & 192 & This study \\
\hline & & $\mathrm{R}$ & GGTGCTCTGTTTGTCCTTGAAG & 351 & & This study \\
\hline \multirow[t]{2}{*}{ R4VF53 } & Cytochrome c553 & $\mathrm{F}$ & GCCTTAGCGACGAGCAGATC & 95 & 148 & This study \\
\hline & & $\mathrm{R}$ & CCTTCGGAGTGGCACTTCTTG & 242 & & This study \\
\hline \multirow[t]{2}{*}{ R4VNL8 } & Cytochrome c552 & $\mathrm{F}$ & GAGCAGGGCAAGGTCTACAC & 886 & 144 & This study \\
\hline & & $\mathrm{R}$ & CTTGAGATCGTGAATGGCATCC & 1,029 & & This study \\
\hline \multirow[t]{2}{*}{ AOKQV7 } & Cytochrome c5 & $\mathrm{F}$ & AAGGATCTGGAAGGGATTGCG & 103 & 112 & This study \\
\hline & & $\mathrm{R}$ & CATCGTGGCAGGCGAAGCAG & 214 & & This study \\
\hline \multirow[t]{2}{*}{ R4VS58 } & Fumarate reductase flavoprotein subunit & $\mathrm{F}$ & TGAACTTCCTCAAGCACACTCTC & 1,615 & 150 & This study \\
\hline & & $\mathrm{R}$ & AGCCATTCTTCTTAGCCTCGTC & 1,764 & & This study \\
\hline \multirow[t]{2}{*}{ R4VNP5 } & Fumarate hydratase & $\mathrm{F}$ & ACCTGCTTCGTCAAGATCGG & 217 & 169 & This study \\
\hline & & $\mathrm{R}$ & GGGCATTGTCCTTGGTGTTC & 385 & & This study \\
\hline
\end{tabular}


Table 2 Sequences of the primer pairs used in this study for q-PCR (Continued)

\begin{tabular}{|c|c|c|c|c|c|c|}
\hline \multirow[t]{2}{*}{ K1JGN0 } & Pyruvate-flavodoxin oxidoreductase & $\mathrm{F}$ & GCTCAGGGCTACTTCGTCTAC & 1,360 & 162 & This study \\
\hline & & $\mathrm{R}$ & CTCCAGCAAGTCTACCGATTCG & 1,521 & & This study \\
\hline \multirow[t]{2}{*}{ GAP-1 } & Glyceraldehyde 3-phosphate dehydrogenase & $\mathrm{F}$ & AGAGCCTCAATGCCTATCTGC & 1,102 & 195 & [53] \\
\hline & & $\mathrm{R}$ & ACCCGAACTCGTTGTCATACC & 1,306 & & [53] \\
\hline
\end{tabular}

\section{Measurement of enzyme activity}

The $\mathrm{H}^{+}$-ATP synthase activities of $A$. hydrophila in $0,150,200$, and $300 \mu \mathrm{M}$ DIP were measured spectrophotometrically at $340 \mathrm{~nm}$ using the $\mathrm{H}^{+}$-ATP synthase assay kit (Genmed Scientifics Inc., MA, USA) according to the manufacturer's protocol, which was based on the oxidation of reduced $\mathrm{NADH}$ to $\mathrm{NAD}^{+}$, by the catalysis of lactate dehydrogenase.

\section{In Vivo exogenous metabolite stimulation assay}

The A. hydrophila strain was diluted at 1:100 in $300 \mu \mathrm{M}$ DIP overnight, with or without 2,4 , and $8 \mathrm{mM}$ oxaloacetic acid (OAA), $\alpha$-ketoglutarate $(\alpha-\mathrm{KA})$, succinic acid (SA), and citric acid (CA) treatment at $30{ }^{\circ} \mathrm{C}$ with shaking at $200 \mathrm{rpm}$. The cell density was determined via optical density (OD) measurement at $600 \mathrm{~nm}$.

\section{$\mathrm{H}^{+}$-ATP synthase inhibition assay}

For the $\mathrm{H}^{+}$-ATP synthase inhibition assay, an orthogonal test was further performed. The A. hydrophila strain was diluted at 1:100 in fresh LB medium with a series of DIP overnight from 0,150, 200 to $300 \mu \mathrm{M}$ and DCCD from 5, 10, to $20 \mu \mathrm{g} / \mathrm{mL}$, respectively. After incubation at $30{ }^{\circ} \mathrm{C}$ for additional $12 \mathrm{~h}$, cells were diluted appropriately with fresh LB medium for bacterial colony counting, which displayed as color grading according to their survival colony accounting with the control normalized to 100 [55].

\section{Statistical analysis}

All Statistical analysis was performed by using One-way ANOVA measurement to compare the different treatments with the control sample.

\section{Additional files}

Additional file 1: Table S1. Identification and quantification results using dimethyl labeling based quantitative proteomics. (XLSX 834 kb)

Additional file 2: Figure S1. Schematic representation of siderophoremediated iron uptake systems and the influence of iron depletion on the cell envelope in A. hydrophila, according to quantitative proteomic analysis. (TIF $2163 \mathrm{~kb}$ )

\section{Abbreviations}

0.2 M Tris- $\mathrm{HCl}$, pH=8.0, 0.5 M sucrose, 1 mM Na2 EDTA, TSE buffer; ABC, ATPbinding cassette; BLAST, Basic local alignment search tool; CA, Citric acid; DCCD, N, N'-Dicyclohexylcarbodiimide; DIP, 2, 2'-dipyridyl; FDR, False discovery rate; GAP-1, Glyceraldehyde-3-phosphate dehydrogenase; GO, Gene Ontology; HCD, High-energy collision dissociation; IAA, lodoacetamide; IMPs, Inner membrane proteins; LB, Luria- Bertani; LC MS/MS, Liquid chromatography tandem mass spectrometry; OAA, Oxaloacetic acid; OD, Optical density; OMPs, Outer membrane proteins; PMF, Proton motive force; q-PCR, Quantitative polymerase chain reaction; ROS, Reactive oxygen species; SA, Succinic acid; TCA, Tricarboxylic acid; TCEP, Tris (2-carboxyethyl) phosphine; TEAB, Triethylammonium bicarbonate;

a-KA, a-Ketoglutarate.

\section{Acknowledgements}

We thank Dr. Jijuan Cao from Liaoning Entry-Exit Inspection and Quarantine Bureau, Dalian, PR. China, who kindly provided Aeromonas hydrophila ATCC 7966 strain.

\section{Funding}

This work was sponsored by grants from NSFC projects (No.31200105, No. 31470238), the Fujian Agricultural and Forestry University Foundation for Distinguished Young Scholars (No. XJQ201201) and Fujian-Taiwan Joint Innovative Center for Germplasm Resources and cultivation of crop (FJ 2011 Program, NO. 2015-75, China).

Availability of data and materials

The proteomics datasets supporting the results of this article are included within the article and its Additional file 2.

\section{Authors' contributions}

$\mathrm{XL}$ and WLin conceived and supervised the project. ZY performed experimental research work. $Z Y$ and $X \mathrm{~L}$ drafted the manuscript. And all listed authors $Z W, L S, W L i, Y S$ and $L L$ aided in the preparation of the manuscript draft, such as LS, WLi performed the statistical analysis, YS, LL coordinated the study and ZW provided great help for manuscript revision. All authors critically reviewed and approved the final version of the manuscript.

\section{Competing interests}

The authors declare that they have no competing interests.

\section{Consent for publication}

Not applicable.

Ethics approval and consent to participate Not applicable.

\section{Author details}

${ }^{1}$ Fujian Provincial Key Laboratory of Agroecological Processing and Safety Monitoring, School of Life Sciences, Fujian Agriculture and Forestry University, Fuzhou 350002, People's Republic of China. ${ }^{2}$ Key Laboratory of Crop Ecology and Molecular Physiology of Fujian Universities, Fujian Agriculture and Forestry University, Fuzhou 350002, People's Republic of China. ${ }^{3}$ Agroecological Institute, Fujian Agriculture and Forestry University, Fuzhou 350002, Fujian, People's Republic of China.

Received: 25 September 2015 Accepted: 12 July 2016

Published online: 22 July 2016

\section{References}

1. Faraldo-Gomez JD, Sansom MS. Acquisition of siderophores in gram-negative bacteria. Nat Rev Mol Cell Biol. 2003;4(2):105-16.

2. Andrews SC, Robinson AK, Rodriguez-Quinones F. Bacterial iron homeostasis. FEMS Microbiol Rev. 2003;27(2-3):215-37.

3. McHugh JP, Rodriguez-Quinones F, Abdul-Tehrani H, Svistunenko DA, Poole RK, Cooper CE, Andrews SC. Global iron-dependent gene regulation in Escherichia coli. A new mechanism for iron homeostasis. J Biol Chem. 2003; 278(32):29478-86 
4. Cornelis P, Wei Q, Andrews SC, Vinckx T. Iron homeostasis and management of oxidative stress response in bacteria. Metallomics. 2011;3(6):540-9.

5. Braun $V$, Hantke $K$. The tricky ways bacteria cope with iron limitation. In: Chakraborty R, Braun V, Hantke K, Cornelis P, editors. Iron uptake in bacteria with emphasis on E coli and pseudomonas. Netherlands: Springer; 2013. p. 31-66.

6. Garenaux A, Caza M, Dozois CM. The Ins and Outs of siderophore mediated iron uptake by extra-intestinal pathogenic Escherichia coli. Vet Microbiol. 2011;153(1-2):89-98.

7. Lin XM, Wu LN, Li H, Wang SY, Peng XX. Downregulation of TsX and OmpW and upregulation of $\mathrm{OmpX}$ are required for iron homeostasis in Escherichia coli. J Proteome Res. 2008;7(3):1235-43.

8. Braun V, Hantke K. Recent insights into iron import by bacteria. Curr Opin Chem Biol. 2011;15(2):328-34.

9. Sprencel C, Cao Z, Oi Z, Scott DC, Montague MA, Ivanoff N, Xu J, Raymond KM, Newton SM, Klebba PE. Binding of ferric enterobactin by the Escherichia coli periplasmic protein FepB. J Bacteriol. 2000;182(19):5359-64.

10. Turlin E, Debarbouille M, Augustyniak K, Gilles AM, Wandersman C. Staphylococcus aureus FepA and FepB proteins drive heme iron utilization in Escherichia coli. PLoS One. 2013;8(2):e56529.

11. Skaar EP. The battle for iron between bacterial pathogens and their vertebrate hosts. PLoS Pathog. 2010;6(8):e1000949.

12. Pridgeon JW, Klesius PH. Molecular identification and virulence of three Aeromonas hydrophila isolates cultured from infected channel catfish during a disease outbreak in west Alabama (USA) in 2009. Dis Aquat Org. 2011; 94(3):249-53.

13. Harikrishnan R, Balasundaram C, Heo MS. Effect of chemotherapy, vaccines and immunostimulants on innate immunity of goldfish infected with Aeromonas hydrophila. Dis Aquat Org. 2009;88(1):45-54.

14. Jeney Z, Racz T, Thompson KD, Poobalane S, Ardo L, Adams A, Jeney G. Differences in the antibody response and survival of genetically different varieties of common carp (Cyprinus carpio L.) vaccinated with a commercial Aeromonas salmonicida/A. hydrophila vaccine and challenged with A. hydrophila. Fish Physiol Biochem. 2009;35(4):677-82.

15. Pandey A, Mann M. Proteomics to study genes and genomes. Nature. 2000; 405(6788):837-46.

16. Hossain MJ, Waldbieser GC, Sun D, Capps NK, Hemstreet WB, Carlisle K, Griffin MJ, Khoo L, Goodwin AE, Sonstegard TS, et al. Implication of lateral genetic transfer in the emergence of Aeromonas hydrophila isolates of epidemic outbreaks in channel catfish. PLoS One. 2013:8(11):e80943.

17. Pieper R, Huang ST, Parmar PP, Clark DJ, Alami H, Fleischmann RD, Perry RD, Peterson SN. Proteomic analysis of iron acquisition, metabolic and regulatory responses of Yersinia pestis to iron starvation. BMC Microbiol. 2010;10:30.

18. Thode SK, Kahlke T, Robertsen EM, Hansen H, Haugen P. The immediate global responses of Aliivibrio salmonicida to iron limitations. BMC Microbiol. 2015;15:9.

19. Zou L, Wang J, Huang B, Xie M, Li A. A solute-binding protein for iron transport in Streptococcus iniae. BMC Microbiol. 2010;10:309.

20. Zhang X, Yang W, Wu H, Gong X, Li A. Multilocus sequence typing revealed a clonal lineage of Aeromonas hydrophila caused motile Aeromonas septicemia outbreaks in pond-cultured cyprinid fish in an epidemic area in central China. Aquaculture. 2014;432:1-6.

21. Master RN, Deane J, Opiela C, Sahm DF. Recent trends in resistance to cell envelope-active antibacterial agents among key bacterial pathogens. Ann N Y Acad Sci. 2013:1277:1-7.

22. Quan S, Hiniker A, Collet JF, Bardwell JC. Isolation of bacteria envelope proteins. Methods Mol Biol (Clifton, NJ). 2013:966:359-66.

23. Higgs PI, Larsen RA, Postle K. Quantification of known components of the Escherichia coli TonB energy transduction system: TonB, ExbB, ExbD and FepA. Mol Microbiol. 2002:44(1):271-81.

24. Stojiljkovic I, Srinivasan N. Neisseria meningitidis tonB, exbB, and exbD genes: Ton-dependent utilization of protein-bound iron in Neisseriae. J Bacteriol. 1997;179(3):805-12.

25. Occhino DA, Wyckoff EE, Henderson DP, Wrona TJ, Payne SM. Vibrio cholerae iron transport: haem transport genes are linked to one of two sets of tonB, exbB, exbD genes. Mol Microbiol. 1998;29(6):1493-507.

26. Moeck GS, Coulton JW. TonB-dependent iron acquisition: mechanisms of siderophore-mediated active transport. Mol Microbiol. 1998;28(4):675-81.

27. Jiang HB, Lou WJ, Ke WT, Song WY, Price NM, Qiu BS. New insights into iron acquisition by cyanobacteria: an essential role for ExbB-ExbD complex in inorganic iron uptake. ISME J. 2015;9(2):297-309.
28. Silhavy TJ, Kahne D, Walker S. The bacterial cell envelope. Cold Spring Harb Perspect Biol. 2010;2(5):a000414.

29. Dumpala PR, Peterson BC, Lawrence ML, Karsi A. Identification of Differentially Abundant Proteins of Edwardsiella ictaluri during Iron Restriction. PLoS One. 2015;10(7):e0132504.

30. Dong $Y, X u X$. Outer membrane proteins induced by iron deficiency in Anabaena sp. PCC 7120. Prog Nat Sci. 2009;19(11):1477-83.

31. Yang W, Ding D, Zhang C, Zhou J, Su X. iTRAQ-based proteomic profiling of Vibrio parahaemolyticus under various culture conditions. Proteome Sci. 2015;13:19.

32. Rushton L, Sass A, Baldwin A, Dowson CG, Donoghue D, Mahenthiralingam E. Key role for efflux in the preservative susceptibility and adaptive resistance of Burkholderia cepacia complex bacteria. Antimicrob Agents Chemother. 2013;57(7):2972-80.

33. Nikaido H. Molecular basis of bacterial outer membrane permeability revisited. Microbiol Mol Biol Rev. 2003;67(4):593-656.

34. Gerding MA, Ogata Y, Pecora ND, Niki H, de Boer PA. The trans-envelope Tol-Pal complex is part of the cell division machinery and required for proper outer-membrane invagination during cell constriction in E. coli. Mol Microbiol. 2007;63(4):1008-25.

35. Lloubes R, Goemaere E, Zhang X, Cascales E, Duche D. Energetics of colicin import revealed by genetic cross-complementation between the Tol and Ton systems. Biochem Soc Trans. 2012;40(6):1480-5.

36. Friedman DB, Stauff DL, Pishchany G, Whitwell CW, Torres VJ, Skaar EP. Staphylococcus aureus redirects central metabolism to increase iron availability. PLoS Pathog. 2006;2(8):e87.

37. Smaldone GT, Revelles O, Gaballa A, Sauer U, Antelmann H, Helmann JD. A global investigation of the Bacillus subtilis iron-sparing response identifies major changes in metabolism. J Bacteriol. 2012;194(10):2594-605.

38. Frawley ER, Fang FC. The ins and outs of bacterial iron metabolism. Mol Microbiol. 2014;93(4):609-16

39. Touati D. Iron and oxidative stress in bacteria. Arch Biochem Biophys. 2000; 373(1):1-6.

40. Koster W. ABC transporter-mediated uptake of iron, siderophores, heme and vitamin B12. Res Microbiol. 2001;152(3-4):291-301.

41. Chu BC, Vogel HJ. A structural and functional analysis of type III periplasmic and substrate binding proteins: their role in bacterial siderophore and heme transport. Biol Chem. 2011;392(1-2):39-52.

42. Cassat JE, Skaar EP. Iron in infection and immunity. Cell Host Microbe. 2013; 13(5):509-19.

43. Yeeles JT, Cammack R, Dillingham MS. An iron-sulfur cluster is essential for the binding of broken DNA by AddAB-type helicase-nucleases. J Biol Chem. 2009;284(12):7746-55.

44. De Alencar TA, Wilmart-Goncalves TC, Vidal LS, Fortunato RS, Leitao AC, Lage C. Bipyridine (2,2'-dipyridyl) potentiates Escherichia coli lethality induced by nitrogen mustard mechlorethamine. Mutat Res 2014:765:40-7.

45. Lee $\mathrm{P}$, Tan KS. Effects of Epigallocatechin gallate against Enterococcus faecalis biofilm and virulence. Arch Oral Biol. 2015:60(3):393-9.

46. Lin X, Kang L, Li H, Peng X. Fluctuation of multiple metabolic pathways is required for Escherichia coli in response to chlortetracycline stress. Mol BioSyst. 2014;10(4):901-8

47. Ross PL, Huang YN, Marchese JN, Williamson B, Parker K, Hattan S, Khainovski N, Pillai S, Dey S, Daniels S, et al. Multiplexed protein quantitation in Saccharomyces cerevisiae using amine-reactive isobaric tagging reagents. Mol Cell Proteomics. 2004;3(12):1154-69.

48. Boersema PJ, Raijmakers R, Lemeer S, Mohammed S, Heck AJ. Multiplex peptide stable isotope dimethyl labeling for quantitative proteomics. Nat Protoc. 2009:4(4):484-94.

49. Nagaraj N, Kulak NA, Cox J, Neuhauser N, Mayr K, Hoerning O, Vorm O, Mann M. System-wide perturbation analysis with nearly complete coverage of the yeast proteome by single-shot ultra HPLC runs on a bench top Orbitrap. Mol Cell Proteomics. 2012;11(3):M111.013722.

50. Kettenbach AN, Deng L, Wu Y, Baldissard S, Adamo ME, Gerber SA, Moseley JB. Quantitative phosphoproteomics reveals pathways for coordination of cell growth and division by the conserved fission yeast kinase pom1. Mol Cell Proteomics. 2015;14(5):1275-87.

51. Gotz S, Garcia-Gomez JM, Terol J, Williams TD, Nagaraj SH, Nueda MJ, Robles M, Talon M, Dopazo J, Conesa A. High-throughput functional annotation and data mining with the Blast2GO suite. Nucleic Acids Res. 2008;36(10):3420-35 
52. Shen HB, Chou KC. Gneg-mPLoc: a top-down strategy to enhance the quality of predicting subcellular localization of Gram-negative bacterial proteins. J Theor Biol. 2010;264(2):326-33.

53. Zampieri D, Nora LC, Basso V, Camassola M, Dillon AJ. Validation of reference genes in Penicillium echinulatum to enable gene expression study using real-time quantitative RT-PCR. Curr Genet. 2014;60(3):231-6.

54. Schmittgen TD, Livak KJ. Analyzing real-time PCR data by the comparative C(T) method. Nat Protoc. 2008;3(6):1101-8.

55. Peng B, Su YB, Li H, Han Y, Guo C, Tian YM, Peng XX. Exogenous alanine and/or glucose plus kanamycin kills antibiotic-resistant bacteria. Cell Metab. 2015;21(2):249-61

Submit your next manuscript to BioMed Central and we will help you at every step:

- We accept pre-submission inquiries

- Our selector tool helps you to find the most relevant journal

- We provide round the clock customer support

- Convenient online submission

- Thorough peer review

- Inclusion in PubMed and all major indexing services

- Maximum visibility for your research

Submit your manuscript at www.biomedcentral.com/submit 